\title{
EFFECT OF LIGHT QUALITIES AND STORAGE PERIODS ON THE GERMINATION OF PENNISETUM POLYSTACHION SEEDS*)
}

\author{
VERAPONGSKIATSOONTHORNand SOEKISMANTJITROSEMITO \\ Department of Biology, Faculty of Science, Srinakhrinwirot University (Prasanmitr), \\ Bangkok 10110, Thailand and \\ SEAMEO BIOTROP, Jl. Raya Tajur Km 6, P.O. Box 17, Bogor, Indonesia.
}

\begin{abstract}
Seeds of the yellowish inflorescence strain of Pennisetum polystachion, collected from the field in Indonesia, were kept in the dark for 30 days, then germinated in 12-h light and 24-h light under various light qualities, namely, white, black, blue, red and far-red. There was no effect of photo-period to seed germination. Percent of seed germination under white, red, far-red, blue and dark were 49, 43, 22, 11 and $2 \%$, respectively. White and red light did not cause any difference to seed germination.

Seeds kept in 12-h light alternating with 12-h dark and 24-h dark for 15 and 30 days were tested for germination. Results showed that light condition during seed storage did not effect seed germination. Long storage period resulted in more seed germination. During seed germination test, effect of light played a great role on increasing seed germination.
\end{abstract}

\section{INTRODUCTION}

Pennisetum polystachion, or mission grass in English (WSSA 1984), in Thailand had two distinctive forms of immature inflorescence colour, namely purplish and yellowish. Studies concerned with seed germination of the yellowish inflorescence strain had been reported (Van Rooden et al. 1970; Noda et al. 1985; Suppaphon et al. 1987; Arunpu et al. 1991). Fernandez (1980) without specifying the immature inflorescence colour, stated that seed of this species collected in Indonesia was photosensitive for germination, especially in the first 70 days of storage after harvest; whereas, Noda et al. (1985) reported that the response of this seed species to light was very low. Arunpu et al. (1991) reported that this species was non-sensitive to light. In order to clarify these discrepencies, the following experiments were conducted.

\footnotetext{
*)This article is part of a six-month research fellowship report submitted to SEAMEO BIOTROP in December 1991.
} 


\section{MATERIALS AND METHODS}

\section{Light qualities and durations}

P. polystachion seeds harvested on 8 July 1991 from BIOTROP experimental field were removed from bristles, screened through a 1-mm-wire mesh to obtain uniform seed sizes and kept in the dark at room temperature $\left(25-29^{\circ} \mathrm{C}\right)$ for 30 days until germination test. One hundred seeds were placed on a filter paper moistened with 4$\mathrm{ml}$ distilled water, in a 9-cm petridish covered with lid. Treatments were designed in factorial of 2 factors: first factor was light period i.e. 12-h light and 24-h light, and another factor was the light qualities, namely white, red, far-red, blue and dark. For light quality treatments each petridish was wrapped with a blue, a red, a blue plus a red transparent polyethylene to obtain blue, red and far-red treatments, respectively (Fernandez 1980). The dishes of dark treatment were wrapped with aluminium foil whereas the white lighted treatment was unwrapped. Light transmission through those transparent polyethylene, measured by specto-photometer is shown in Fig. 1. These dishes were placed in a $25-29^{\circ} \mathrm{C}$ room illuminated with $24-\mathrm{h}$ light by cool fluorescent tubes Philips TLD 36 W. Light
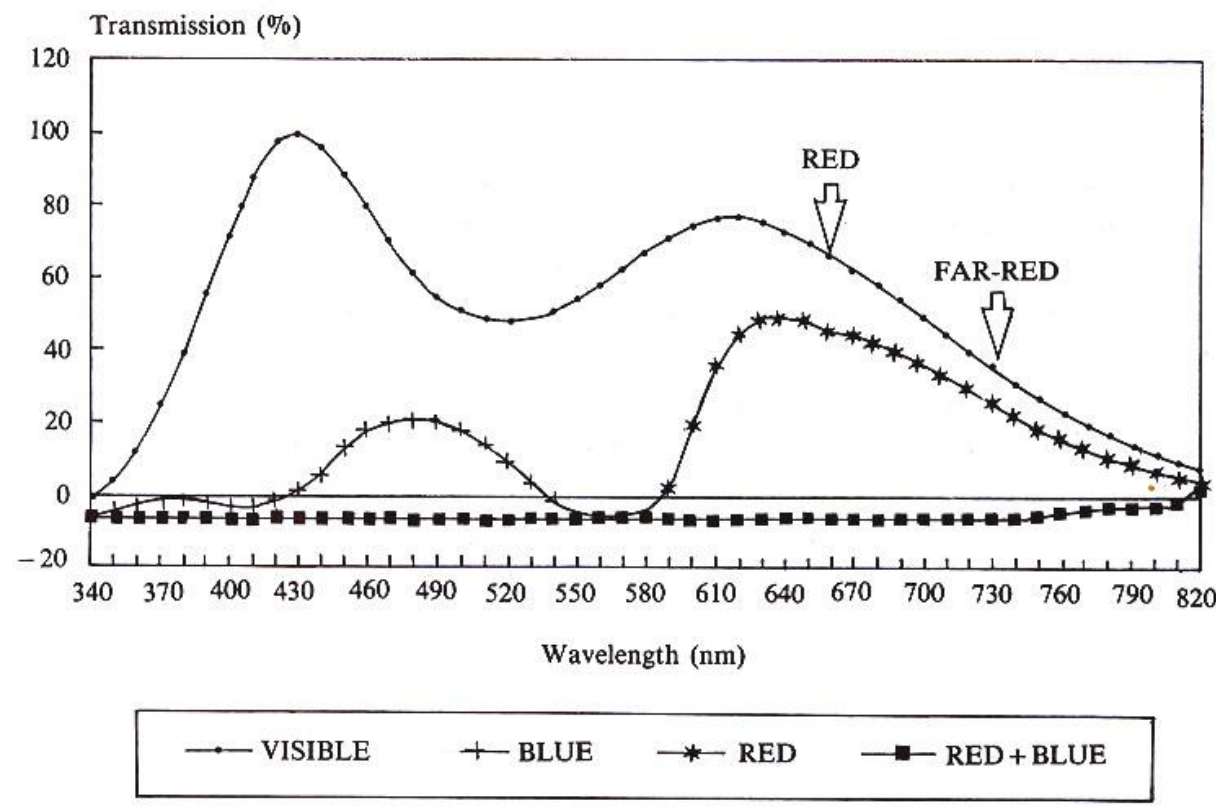

Fig. 1. Percentage transmission of light through red, blue, and red plus blue transparent polyethylenes from tungstar light source 
intensity reaching the dishes through red, blue, and red plus blue transparent polyethylene was $0.066,0.073,0,004 \mathrm{UEM}^{-2} \mathrm{~s}^{-1}$, respectively, whereas the controlled light was 0.775 $\mathrm{UEM}^{-2} \mathrm{~s}^{-1}$. For the 12-h lighted treatment, those dishes were covered with an opaque container for 12-h dark alternating with 12-h light. During the experimental period the dishes were randomly rotated in order to reduce the effect of different light intensities. Germination was tested 6 days after treatments and was transformed to arcsine square root before statistical analysis.

\section{Storage period, light conditions during seed storage and germination test}

\subsection{Effect of lighted conditions during storage and storage period lighted}

The experiment was replicated 4 times in factorial design with 2 factors: the first factor was the storage period of 15 and 30 days; the second factor was light conditions during storage consisting of the dark and light/dark conditions.

$P$. polystachion seeds collected from the same location as in experiment 1 , on 20 August 1991, were kept in a 24-h dark (dark) or 12-h light alternating with 12-h dark (light/dark). For the dark treatment, seeds were placed in polyethylene bag and wrapped with aluminium foil; while for the light condition, the polyethylene bag was not wrapped with aluminium foil. Both treated seeds were separately kept in 9-cm petridishes, placed on a table near the window for 15 and 30 days until germination. Germination test was done in a $30^{\circ} \mathrm{C}$ controlled incubator illuminated with 12 -h light alternating with 12-h dark. Light intensity during the day was $1.32 * 10^{-4} \mathrm{UEM}^{-2} \mathrm{~s}^{-1}$. The detailed methods were the same as mentioned in experiment 1 . Accumulated number of seed germination at 8th day were transformed to arcsine square root before statistical analysis.

\subsection{Effect of lighted conditions during storage and germination methods}

Seeds stored in light/dark and dark conditions for 30 days, as in experiment 2.1, were used. The experiment was replicated 4 times in factorial design with 2 factors: the first factor was light condition, consisting of the dark, and the light/dark condition for 30 days; the second factor was germinating condition consisting of alternating 12-h lighted with 12-h dark with data collected every 2 days up to 8 days (light/2), dark condition with data collected every 2 days up to 8 days (dark/2), and dark condition with data collected 8 days later (dark/8). For seeds germinated in the dark/2 and dark conditions, petridishes were wrapped with aluminium foil. Germinated seed counting was done in dark room under green light (40 watt incadescent bulb wrapped with a green transparent polyethylene).

In both experiments, accumulated data of seed germinated at 8 days after treatments were transformed to arcsine and statistically analyzed. 


\section{RESULTS AND DISCUSSION}

\section{Effect of light qualities and durations}

Results of this experiment showed that exposure of 24-h light and 12-h light did not cause any difference on seed germination. Percent germination of seeds under white, red, far-red, blue light and dark conditions were 49, 43.1, 21.9, 11.1 and 1.6\%, respectively, whereas red and white light treatments similarly effected seed germination (Figure 2).

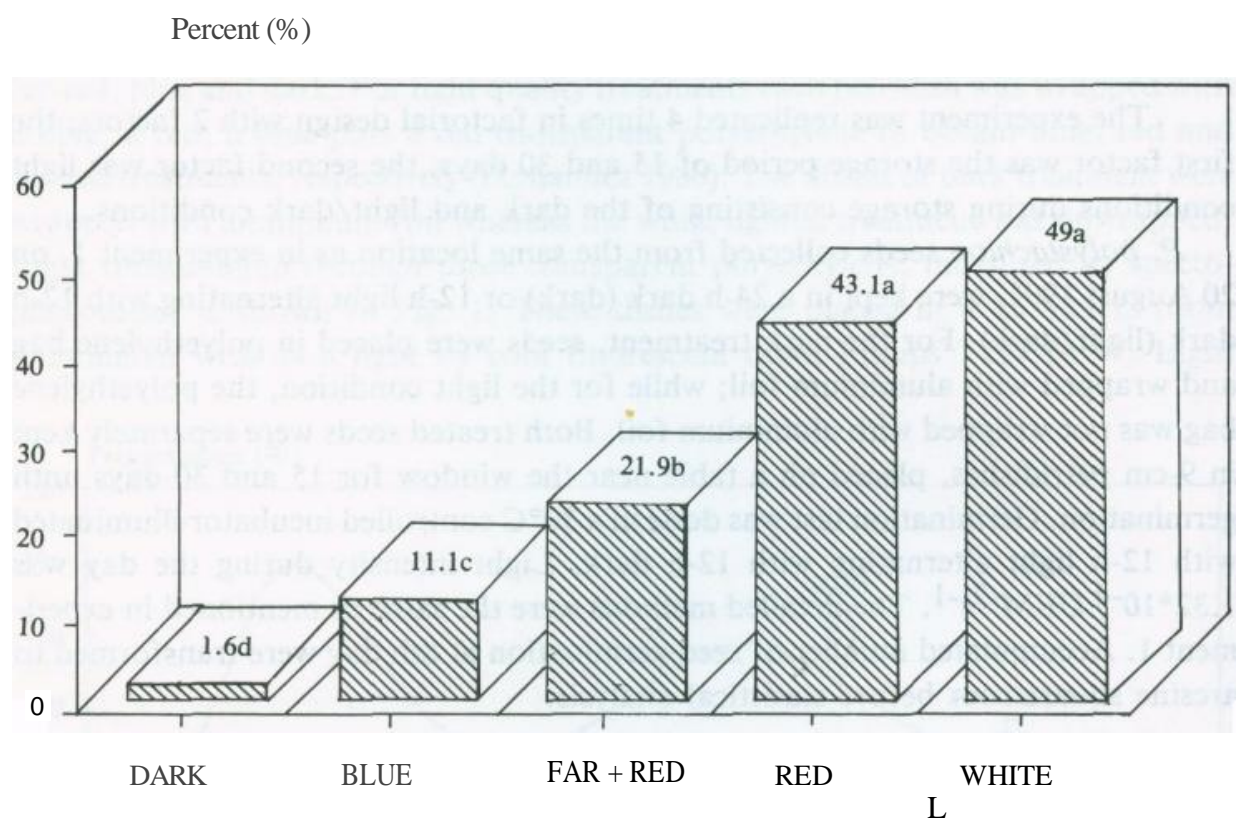

Light qualities

Fig. 2. Germination of $P$. polystachion seeds under various light qualities (30 days after seeds collection)

Light qualities and photo-period did not interact to effect seed germination (Figure 3). The result of seed germination under various light qualities in this experiment was similar to Fernandez's result (1980) except the effects of blue and far-red which were significantly different in this result but not different in Fernandez's. One form of phytochrome in seed, phytochrome far-red (Pfr), which is an active form for seed germination, can be transformed from phytochrome red (Pr) when irradiated with red light; and Pfr can be transformed back to Pr when irradiated with far-red light (Taylorson 1987). Pfr can also degenerate to Pr in the 
Effect of light qualities and storage periods - Verapongs Kiatsoonthorn \& Soekisman Tjitrosemito

Fig. 3. Seed germination of $P$. polystachion effected by light qualities and photo-periods (nonsignificant between the interaction factors)

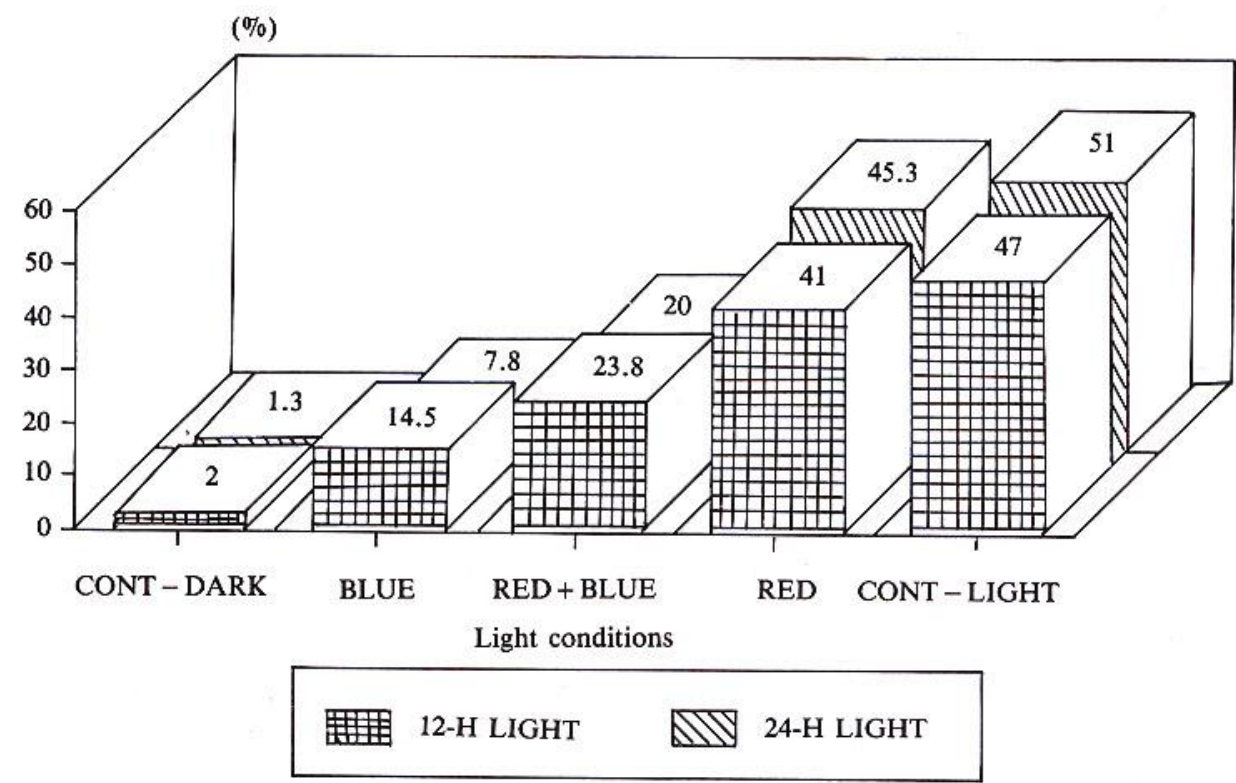

dark. This explains why red and white lights showed higher germination than the dark condition. Blue and red transparancies apparently permitted transmission of red light better than blue transparancy, therefore the former stimulated more germination than the later. Although blue transparancy transmitted wavelength between 430-550 nm (Fig. 1), this light has not been reported to affect germination. In Fernandez's method, the light intensities were different from the other because some petridishes were covered with various transparancies, while the distance between the light source and petridishes were similar.

\section{Storage period, light conditions during seed storage and germination test}

\subsection{Effect of lighted conditions during storage, and storage period}

$P$. polystachion seeds kept in room temperature for 15 days had lower germination percentage than those kept for 30 days (Table 1). However, different light conditions during seed storage did not show any different effect on seed germination. Light condition and period during seed storage did not interact to affect seed germination. 
Table 1. Percent germination of seeds kept in two different lighted conditions for 15 and 30 days (8 days after treatments)

\begin{tabular}{lccc}
\hline \hline \multirow{2}{*}{$\begin{array}{l}\text { Periods } \\
\text { (days) }\end{array}$} & \multicolumn{2}{c}{ Conditions during storage } & \multirow{2}{*}{ Mean } \\
\cline { 2 - 3 } & Light/Dark & Dark & \\
\hline 15 & 72.0 & 70.2 & $71.13 \mathrm{a}^{*}$ \\
30 & 83.7 & 82.5 & $83.13 \mathrm{~b}$ \\
\cline { 2 - 3 } Mean & $77.8 \mathrm{a}$ & $76.3 \mathrm{a}^{*}$ & \\
\hline
\end{tabular}

* Mean values followed by the same letter are not significantly different at the $5 \%$ level.

\subsection{Effect of lighted conditions during storage and germination methods}

The result of this experiment supports that of experiment 2.1., i.e. the light condition during seed storage did not affect seed germination. However, different germinating methods effected seed germination differently. More seeds germinated in light/2 than in dark/2 or dark/8. In dark condition, those seeds observed for germination every 2 days had higher germination than those observed only once at 8 days after germination (Table 2). The green transparancy may be able to transmit some red light, which stimulates germination. However, both factors of light conditions during seed storage and of germinating methods did not have any interaction on the number of germinated seeds.

The difference in seed germination under light and dark condition found in this experiment was similar to Fernandez's result (1980) and Noda et al. (1985); but was contrary to Arunpu et al. (1991). It was reasoned that seeds used in the experiment of Arunpu et al. were kept for too long $\left(6\right.$ months at $5^{\circ} \mathrm{C}$ dark condition $)$ so photo-sensitivity of seed was lost.

Table 2. Percent germination of seeds effected by lighted conditions during storage and germinatimg methods ( 8 days after treatments)

\begin{tabular}{llll}
\hline \hline \multirow{2}{*}{$\begin{array}{l}\text { Germinating } \\
\text { conditions }\end{array}$} & \multicolumn{2}{c}{ Conditions during storage } & \multirow{2}{*}{ Mean } \\
\cline { 2 - 3 } & Light & Dark & \\
\hline Light/2 & 83.7 & 82.5 & $83.1 \mathrm{a}^{*}$ \\
Dark/2 & 66.2 & 68.7 & $67.5 \mathrm{~b}$ \\
Dark/8 & 53.5 & 47.0 & $50.2 \mathrm{c}$ \\
\cline { 2 - 3 } Mean & $67.8 \mathrm{a}$ & $66.0 \mathrm{a}^{*}$ & \\
\hline
\end{tabular}

* Mean values followed by the same letter are not significantly different at the $5 \%$ level. 
Effect of light qualities and storage periods - Verapongs Kiatsoonthorn \& Soekisman Tjitrosemito

\section{REFERENCES}

ARUNPU, S., V. KIATSOONTHORN and Y. YINGWIWATANAPONG. 1991. Effect of Some Environmental Factors on Seed Germination of $P$. setosum (Swartz) L.C. Rich. Kasetsart Journal (Abstract in English). In press.

FERnANDEZ, D.B. 1980. Some Aspects on the Biology of Pennisetum poylstachyon (L.) Schult. Philippine Journal of Weed Science 7: 1-10.

NODA, K., L. CHAIWIRATNUKUL, S. KANJANAIRAWONGand M. TEERAWATSAKUL. 1985. Some Biological Characteristics of Pennisetum spp. in Thailand. Proceeding of $10^{\text {th }}$ Asian-Pacific Weed Science Society Conference: 75-80.

SUPPAPHON, J., P. ROENGAPAPONG and CHITPONG. 1987. Certain Characteristics of Flower and Seed Germination of Pennisetum setosum. In: Report of Workshop on Pennisetum setosum, held by Prince of Songkla University and Ministry of Agriculture and Cooperatives in cooperation with Agricultural Science Association of Thailand under the Royal Patronage, Pesticide Business Association of Thailand, and Weed Science Society of Thailand: 19-32. (Abstract in English).

TAYLORSON, R.B. 1987. Environmental and Chemical Manipulation of Weed Seed Dormancy. In: Review of Weed Science. Weed Science Society of America Vol. 3: 135-154

VAN ROODEn, J., L.M.A. AKKERMANS and R. VAN DER VEEN. 1970. A Study on Photoblastism in Seeds of Some Tropical Weeds. Acta. Bot. Neerl. 19(2): 257-264.

WSSA. 1984. Composite List of Weeds. Weed Science Vol. 32 (Supplement 2). 